\title{
Three-step operation for esophago-left bronchial fistula with respiratory failure after esophagectomy: a case report with literature review
}

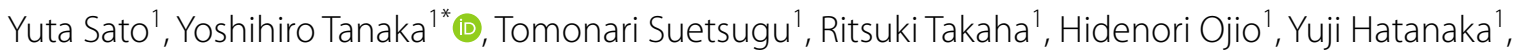 \\ Takeharu Imai ', Naoki Okumura', Nobuhisa Matsuhashi' , Takao Takahashi', Hisakazu Kato² and \\ Kazuhiro Yoshida?
}

\begin{abstract}
Background: The development of esophago-bronchial fistula after esophagectomy and reconstruction using a posterior mediastinal gastric tube remains a rare complication associated with a high rate of mortality.

Case presentation: A 63-year-old man with esophageal cancer underwent a thoracoscopic esophagectomy with two-field lymph node dissection and reconstruction via a gastric tube through the posterior mediastinal route. Postoperatively, the patient developed extensive pyothorax in the right lung due to port site bleeding and hematoma infection. Four months after surgery, he developed an esophago-left bronchial fistula due to ischemia of the cervical esophagus and severe reflux esophagitis at the site of the anastomosis. Because of respiratory failure due to the esophago-bronchial fistula and the history of extensive right pyothorax, right thoracotomy and left one-lung ventilation were thought to be impossible, so we decided to perform the surgery in three-step systematically. First, we inserted a decompression catheter and feeding tube into the gastric tube as a gastrostomy and expected neovascularization to develop from the wall of the gastric tube through the anastomosis after this procedure. Second, 14 months after esophagectomy, we constructed an esophagostomy after confirming blood flow in the distal side of the cervical esophagus via gastric tube using intraoperative indocyanine green-guided blood flow evaluation. In the final step, we closed the esophagostomy and performed a cervical esophago-jejunal anastomosis to restore esophageal continuity using a pedicle jejunum in a Roux-en-Y anastomosis via a subcutaneous route.
\end{abstract}

Conclusion: This three-step operation can be an effective procedure for patients with esophago-left bronchial fistula after esophagectomy, especially those with respiratory failure and difficulty in undergoing right thoracotomy with left one-lung ventilation.

Keywords: Esophageal cancer, Esophagectomy, Esophago-bronchial fistula, Esophagostomy, Three-step method

*Correspondence: yoshihirotana11@hotmail.com

1 Department of Gastroenterological Surgery and Pediatric Surgery, Gifu

University Graduate School of Medicine, Gifu City, Japan

Full list of author information is available at the end of the article

\section{Background}

Esophago-bronchial fistula (EBF) is a rare but life-threatening complication after subtotal esophagectomy with gastric tube reconstruction via the posterior mediastinal route. Refractory EBF necessitates a surgical procedure, which generally requires a thoracotomy and one-lung 
ventilation to approach the fistula. However, such procedures might be too invasive for patients with pneumonia and respiratory failure caused by the EBF. We report a rare case of EBF after esophagectomy for esophageal cancer that was successfully treated by a three-step operation without thoracotomy. The first step aimed at improving pneumonia and nutritional status and expected neovascularization to develop from the wall of the gastric tube through the anastomosis, the second created an esophagostomy using intraoperative indocyanine green (ICG) to evaluate blood flow through the anastomosis, and the third restored esophageal continuity using an esophago-jejunal bypass.

\section{Case presentation}

A 63-year-old man was diagnosed as having advanced esophageal cancer by upper endoscopy after a chief complaint of dysphagia. The tumor was located in the lower thoracic esophagus and a biopsy revealed squamous cell carcinoma. His body weight was $98 \mathrm{~kg}$ and body mass index was $30.2 \mathrm{~kg} / \mathrm{m}^{2}$. Preoperative diagnosis of the tumor was T3N1M0 Stage III according to the TNM classification of the Union for International Cancer Control [1]. After he received two courses of bi-weekly DCF (docetaxel $35 \mathrm{mg} / \mathrm{m}^{2}$, cisplatin $40 \mathrm{mg} / \mathrm{m}^{2}$, and fluorouracil $400 \mathrm{mg} / \mathrm{m}^{2}$ ) [2,3] as neoadjuvant chemotherapy, we performed thoracoscopic esophagectomy with two-field lymphadenectomy, subtotal stomach reconstruction via the posterior mediastinal route, and jejunostomy. The cervical esophago-subtotal stomach anastomosis was created via the hand-sewn method. On postoperative day (POD) 7, the patient complained of high fever and cough, and chest X-ray and computed tomography (CT) revealed a right pyothorax and air leakage (Fig. 1a, b). Upper gastrointestinal imaging showed no anastomotic leakage. Also, multiple right thoracic cavity drainage was performed, but no turbulent fluid flow was obtained from the thoracic tube. Therefore, we considered that the extensive pyothorax and pneumothorax had developed due to port site bleeding and hematoma infection. After conservative therapy including drainage and antibiotics, the inflammation gradually improved. The patient resumed oral intake on POD 14 and was discharged from hospital on POD 31. He was admitted to another hospital with pneumonia once after esophagectomy and treated with antibiotics.

Four months after surgery, he was re-admitted due to dyspnea, chronic cough, fever, and dysphagia. A blood gas analysis on admission reveled respiratory failure with a partial pressure of arterial oxygen of $59.2 \mathrm{mmHg}$ and a partial pressure of arterial carbon dioxide of $36.8 \mathrm{mmHg}\left(\mathrm{O}_{2}, 6 \mathrm{~L} / \mathrm{min}\right)$, and $\mathrm{CT}$ images
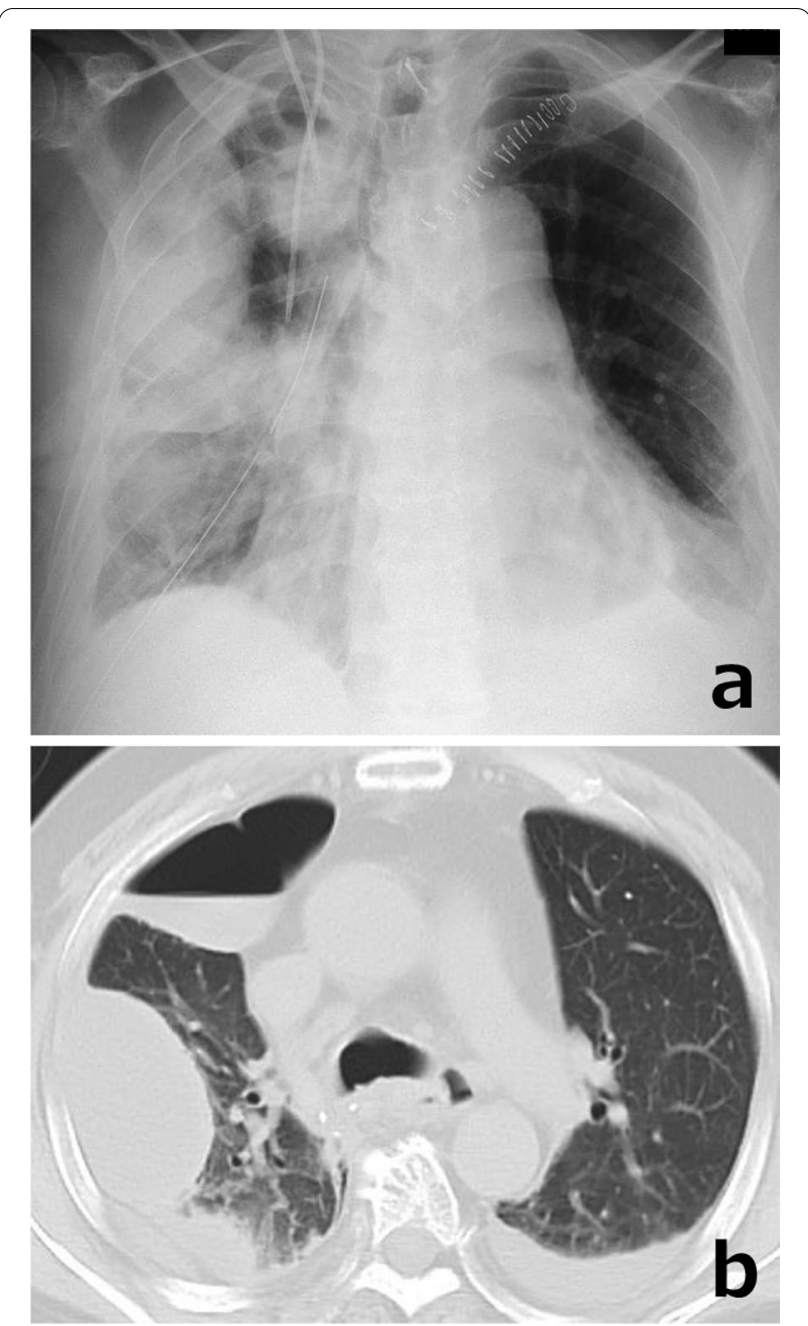

Fig. 1 Chest X-ray and CT images on POD 7. a Lobar pneumonia of the right lung and pyothorax of the right middle and upper lobes. b Multiple pyothoraces, pneumonia and pneumothorax of the right lung and bilateral pleural effusion

revealed severe bilateral pneumonia and pneumotho$\operatorname{rax}$ (Fig. 2a). A Gastrografin contrast study showed a persistent fistulous tract between the gastric tube and the left main bronchus (Fig. 2b). Upper endoscopy showed a circumferential ulcer of the esophagus proximal to the anastomosis and a fistula in the anterior wall of the distal esophagus (Fig. 2c). After these examinations, a nasogastric drainage tube and nutritional feeding tube from the nose to the duodenum were inserted, and treatment against pneumonia and the esophageal ulcer using a proton pump inhibitor was performed for 1 month. Although the esophageal ulcer shrank and the EBF had become slightly smaller after this treatment (Fig. 2d), digestive fluid and sputum frequently refluxed into the lung, and the respiratory disorder remained. 


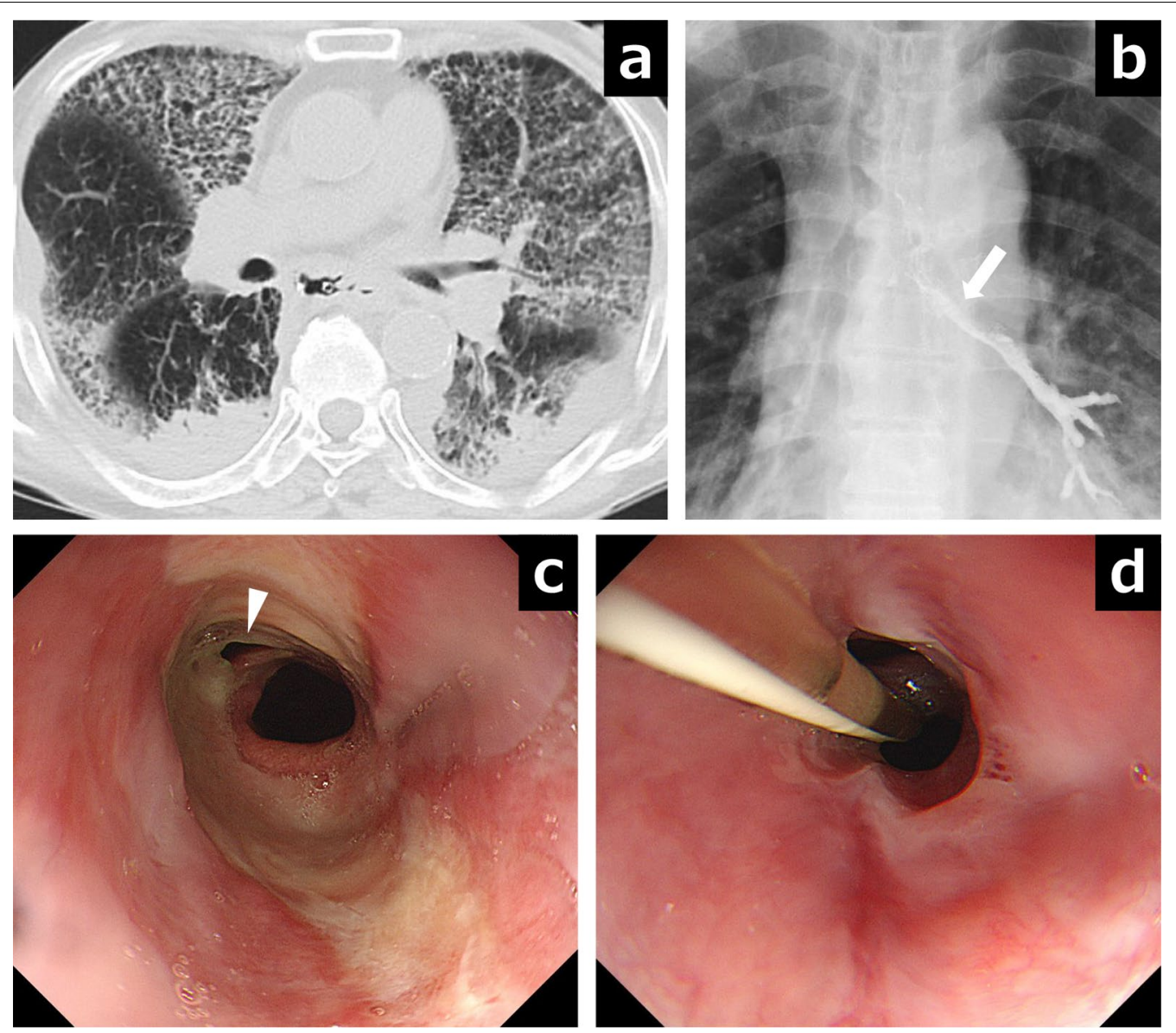

Fig. 2 The findings of esophago-left bronchial fistula are shown. a CT images showed bilateral severe pneumonia. b Gastrografin contrast study showed leakage into the left main bronchus (white arrow). c A fistula (white arrowhead) was detected in the anterior wall of the esophagogastric anastomotic area by upper endoscopy. d The esophageal ulcer shrank, but the fistula did not close after 1 month

We considered that right thoracotomy would be too invasive and dangerous for patient who developed extensive right pyothorax after esophagectomy. We also considered separating the respiratory and gastrointestinal tracts by constructing an esophagostomy, but this method could cause severe mediastinitis due to the loss of blood flow in the esophagus after esophagectomy. Therefore, we decided to perform a three-step operation for this EBF.

The first procedure was aimed at maintaining stable tube nutrition and continuous drainage of digestive fluid in the gastric tube to improve his pneumonia. We inserted a decompression catheter into the gastric tube as a gastrostomy and a feeding tube to the jejunum from the gastric tube by laparotomy under general anesthesia (Fig. 3). This operation enabled stable nutritional management and treatment of pneumonia, and although there were two tubes in the abdomen, the nasogastric tubes could be removed, allowing the patient to be discharged temporarily. However, over the next 9 month, he repeatedly developed aspiration pneumonia.

The second procedure was performed 14 months after the esophagectomy to bring the cervical esophagus to the left cervical region as an esophagostomy (Fig. 4a). We performed intraoperative ICG-guided evaluation of blood flow through the anastomosis in the hope of confirming blood supply by collateral circulation through the anastomotic line from the gastric tube. The esophagus was taped at the left neck, the planned esophagostomy site was clamped, and ICG $25 \mathrm{mg} / 5 \mathrm{~mL}$ was gently injected via the peripheral blood route. The ICG fluorescence was detected with near-infrared light visualization (Stryker Co., Kalamazoo, USA). Within about $30 \mathrm{~s}$ after the ICG solution was injected, blood flow in distal side of the esophagus was confirmed from the gastric tube through the esophagogastric anastomosis (Fig. 4b). This procedure prevented dripping of oral saliva and digestive fluid and eliminated direct inhalation of digestive fluid via 


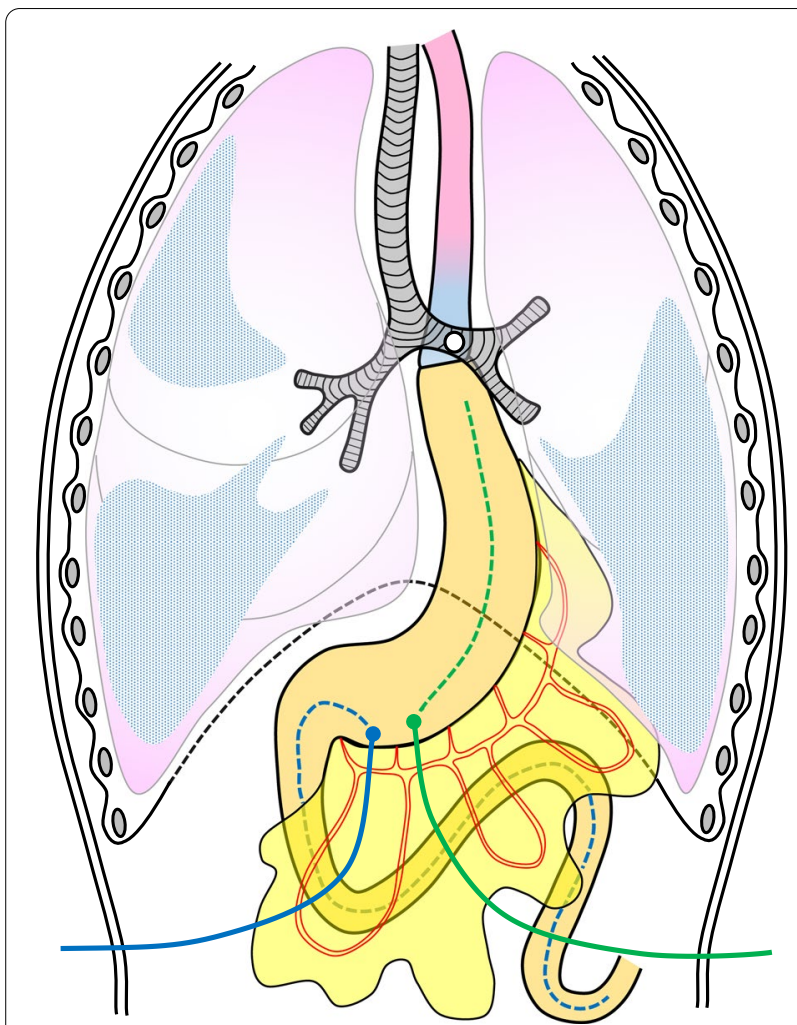

Fig. 3 Schema of the first procedure of the three-step operation. A decompression catheter (green line and dotted line) and a feeding tube (blue line and dotted line) were inserted via gastrostomies in the gastric tube the esophago-bronchial fistula, following which the patient then underwent 3 months of physical rehabilitation and nutritional support to prepare for reversal of the esophageal discontinuity.

The third procedure was performed 17 months after the esophagectomy. The esophagus was reconstructed using a pedicle jejunum in a Roux-en-Y anastomosis via a subcutaneous route. After confirming sufficient blood flow, the second and third branches of the jejunal artery and vein were ligated, and a long segment of the jejunum was pulled up subcutaneously. Microvascular anastomoses of the right internal thoracic arteriovenous and second jejunal arteriovenous vessels were performed by plastic surgeons. The esophagostomy was closed, the cervical esophagus and the lifted jejunum were manually anastomosed, and the end of the pedicled jejunum was anastomosed to the jejunum in a Roux-en-Y configuration (Fig. 5). Oral intake was started on POD 7, and a barium swallow study showed smooth oral intake. The patient was discharged on POD 31.

\section{Discussion and conclusions}

Most of case series on EBF after esophagestomy are from late 1990s onward, and it is a very rare complication with an incidence of $0.26-3.15 \%$ [4-15]. EBF is one of the most difficult complications to deal with after esophagectomy and reconstruction via a gastric tube thorough the posterior mediastinal route. Development of EBF compromises the integrity of both the airway and the digestive tract, resulting in respiratory failure due to severe aspiration pneumonia, and even with surgery, postoperative mortality is very high (Table 1).

Various causes of EBF such as anastomotic leakage, gastric tube necrosis, ulcer of the stomach, and bronchial ischemia have been reported. We consider the direct cause of the EBF in our case to be ischemia occurring at the distal end of the esophagus and severe reflux esophagitis. The patient was obese and had a thick neck, and the esophagus remained too long due to the patient's physique when the esophagus and gastric tube were manually anastomosed in the neck. Furthermore, because we had dissected the esophageal branches of the inferior thyroid artery and tracheoesophageal arteries, which supply blood to the cervical esophagus during upper mediastinum dissection [16], we speculated that poor blood flow to the anastomotic site, which reached the level of the tracheal bifurcation, combined with severe reflux esophagitis caused by the intrathoracic anastomosis, may have resulted in ulceration and fistula formation.

Surgical treatment generally consists of a direct approach with dissection of the fistula and closure of the bronchial and gastric tube defects, but there is no established surgical procedure. Shen et al. [7] described that single-stage primary repair of tracheoesophageal fistula with tissue flap interposition can safely be performed successfully in the majority of patient. On the other hand, some reports classify fistula according to type and location, and suggest that the indications for surgery should be carefully determined $[10,15]$. The interposed vital tissue used for repair are similarly varied, with latissimus dorsi muscle flap, major pectoral muscle flap, pericardial flap and pedicled muscle flap being reported [12,17].

These repairs of the EBF usually require right thoracotomy and left one-lung ventilation. However, when an esophageal left bronchial fistula is formed, as in our case, there are two important problems.

The first is that the anesthesia for left one-lung ventilation required for right thoracotomy is highly difficult due to the location of the fistula and preoperative pneumonia. Moreover, for patients who are in severe respiratory failure preoperatively due to EBF, general anesthesia itself is very invasive and risky. Second, even if an esophagostomy is performed to separating the respiratory and gastrointestinal tracts to control the aspiration pneumonia, 


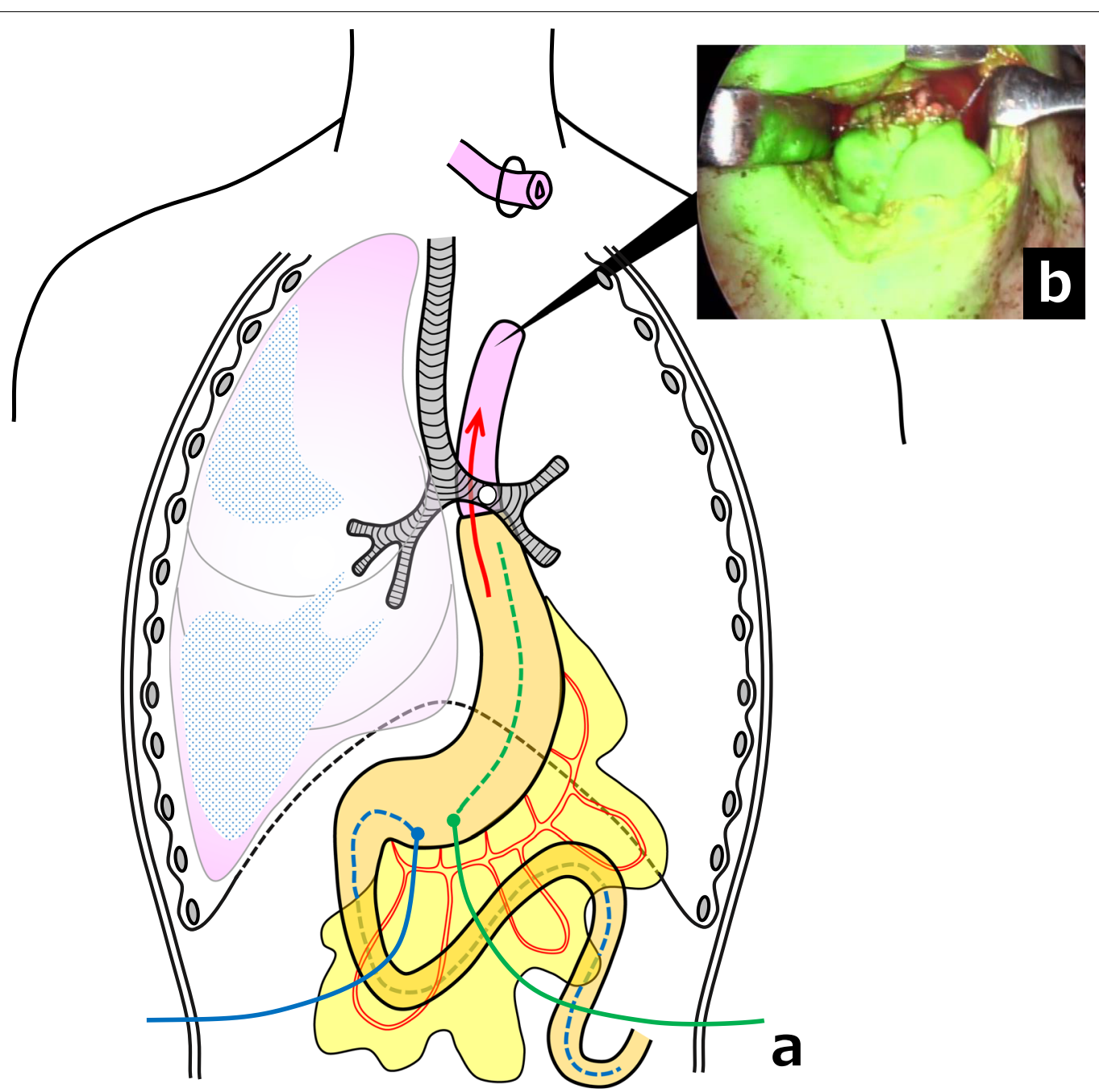

Fig. 4 Schema of the second procedure of the three-step operation. a The cervical esophagus was brought to the left cervical region as an esophagostomy. $\mathbf{b}$ Inflow of ICG is apparent from the gastric tube through the esophagogastric anastomosis

residual esophagus, including the EBF that has lost blood flow remains in the mediastinum. Initially we considered a two-step operation for separate the respiratory and gastrointestinal tracts by constructing an esophagostomy at the left cervical region without thoracotomy to prevent dripping of oral saliva. However, we decided that it would be impossible to dissect the esophagus to the tracheal bifurcation and pull it up to the neck using only the cervical approach. Therefore, we selected a safe surgical approach without thoracotomy that is systematically divided into three-step.

Several Successful cases of multi-step operation have been reported as a surgical strategy for patients who have difficulty with thoracotomy, which was partially similar to our treatment concept $[18,19]$. Bamba et al. [18] successfully performed a three-step operation for esophagorespiratory fistula following airway stenting for stenosis of tracheal anastomosis, but blood flow to the remaining esophagus in the mediastinum was maintained via the proper esophageal artery, which was different from our case. Ibuki et al. [19] performed a two-step operation for EBF after esophagectomy, but unlike our case, they were able to dissect the entire esophagus using only the cervical approach.

There are several case reports of fully developed neovascularization from the gastric tube to the anastomosis, which is an important finding to ensure blood flow in the residual esophagus, the second problem [20-22]. Hara et al. [20] reported a successful case of distal part resection of gastric duct cancer after esophagectomy by blood flow evaluation and stated that the interval from esophagectomy to neovascularization was a minimum of 10 months and a maximum of 154 months, but less than one year is very rare. For this reason, we decided 


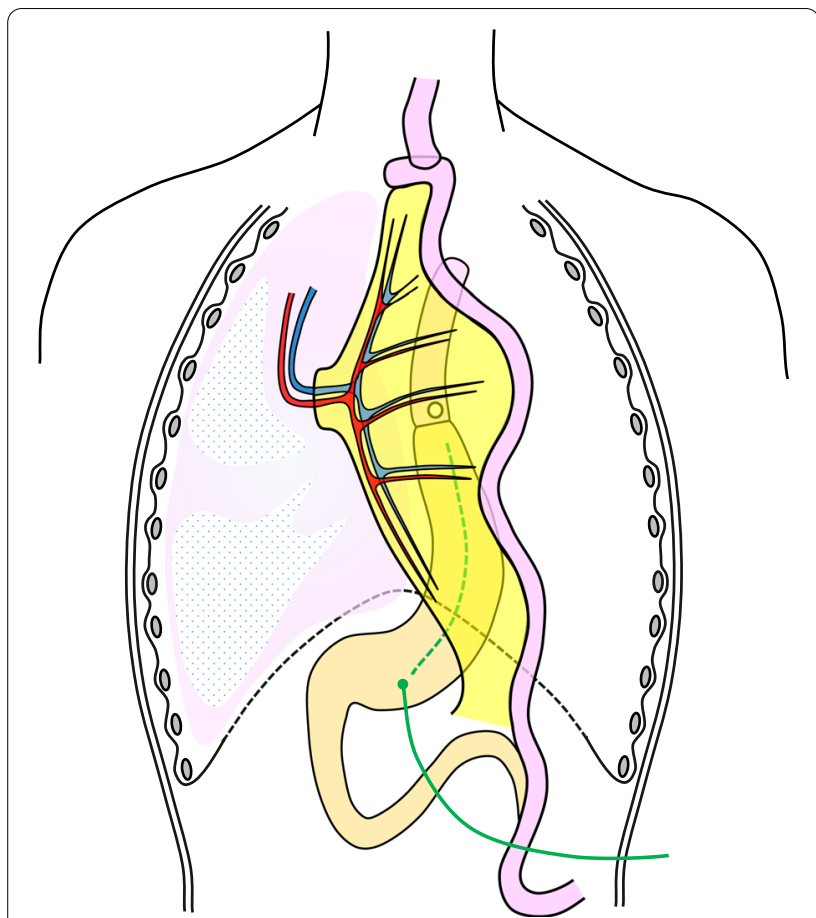

Fig. 5 Schema of the final procedure of the three-step operation. The esophagus was reconstructed using a pedicle jejunum in a Roux-en-Y anastomosis via a subcutaneous route with microvascular anastomosis of the right internal thoracic vessels and the second jejunal vessels
Table 1 Comparison of recent reports describing the management of fistula between the airway and reconstructed conduit after esophagectomy

\begin{tabular}{|c|c|c|c|c|}
\hline Autor [reference] & Data & $\begin{array}{l}\text { Patients } \\
\text { with } \\
\text { fistula }\end{array}$ & Incidence (\%) & $\begin{array}{l}\text { Operative } \\
\text { mortality } \\
\text { (\%) }\end{array}$ \\
\hline Bartels et al. [4] & 1998 & 31 & 0.51 & $\mathrm{n} / \mathrm{a}$ \\
\hline Buskens et al. [5] & 2001 & 6 & 0.26 & 0/4 (0) \\
\hline Mangi et al. [6] & 2002 & 2 & $\mathrm{n} / \mathrm{a}$ & $0 / 2(0)$ \\
\hline Shen et al. [7] & 2010 & 11 & $\mathrm{n} / \mathrm{a}$ & $2 / 35\left(5.7^{*}\right)$ \\
\hline Yasuda et al. [8] & 2012 & 10 & 1.65 & $3 / 6(30)$ \\
\hline Schweigert et al. [9] & 2012 & 7 & 3.15 & $2 / 2(100)$ \\
\hline Kuwabara et al. [10] & 2013 & 9 & 1.89 & $1 / 4(25)$ \\
\hline Wang et al. [11] & 2014 & 7 & 0.64 & $2 / 3(66.8)$ \\
\hline Morita et al. [12] & 2015 & 6 & 0.26 & $0 / 2(0)$ \\
\hline Lambertz et al. [13] & 2016 & 13 & 1.08 & $4 / 7(57.1)$ \\
\hline Balakrishnan et al. [14] & 2018 & 3 & 0.28 & $\mathrm{n} / \mathrm{a}$ \\
\hline Changchu et al. [15] & 2020 & 26 & 0.41 & $11 / 26(42.3)$ \\
\hline
\end{tabular}

n/a not available

*Mortality rate regarding the total number of 35 patients with fistula to allow 14 months for esophagostomy. For this reason, we decided to allow 14 months for esophagostomy.

In the three-step operation we performed, the first procedure improved the pneumonia by maintaining tube nutrition and draining digestive fluid in the gastric tube. This also allowed time for neovascularization to develop from the wall of the gastric tube through the anastomosis. In the second procedure, ICG-guided blood flow evaluation of the distal side of the esophagus enabled prevention of oral saliva dripping and upstream regurgitation from the stomach through creation of the esophagostomy. Finally, after the patient underwent physical rehabilitation and nutritional management, the third procedure was performed to restore esophageal continuity using an esophago-jejunal bypass.

If a patient's general condition is good, we may perform the second and third procedure at the same time. In recent years, successful cases of endoscopic fistula closure have been reported [23, 24], and this may become a treatment option. However, we did not choose endoscopic treatment in our case because we were concerned that aspiration pneumonia and respiratory failure due to the EBF would be exacerbated by endoscopic insufflation.

This three-step operation resulted in a favorable outcome for our patient with EBF after esophagectomy. This approach can be safe and useful in patients with respiratory failure due to $\mathrm{EBF}$, especially those in whom right thoracotomy with left one-lung ventilation would be difficult to perform.

\section{Abbreviations}

CT: Computed tomography; EBF: Esophago-bronchial fistula; ICG: Indocyanine green; POD: Postoperative day.

\section{Acknowledgements}

We thank Rise Japan LLC for the English language editing.

\section{Authors' contributions}

YS drafted the manuscript. YT, TS, and RT performed the operation. $\mathrm{HO}, \mathrm{YH}, \mathrm{TI}$, and $\mathrm{HK}$ participated in the operation. NO, NM, TT, and KY provided academic advice. All authors read and approved the final manuscript.

Funding

Funding information is not applicable.

\section{Availability of data and materials}

Not applicable.

\section{Declarations}

\section{Ethics approval and consent to participate}

This case report was approved by the ethics committee of Gifu University School of Medicine.

\section{Consent for publication}

Written informed consent was obtained from the patient for publication of this case report and accompanying images. A copy of the patient's written consent is available for review by the Editor-in-Chief of this journal. 


\section{Competing interest}

Yuta Sato, Yoshihiro Tanaka, Tomonari Suetsugu, Ritsuki Takaha, Hidenori Ojio, Yuji Hatanaka, Takeharu Imai, Naoki Okumura, Nobuhisa Matsuhashi, Takao Takahashi, Hisakazu Kato, and Kazuhiro Yoshida declare that they have no conflict of interest.

\section{Author details}

${ }^{1}$ Department of Gastroenterological Surgery and Pediatric Surgery, Gifu University Graduate School of Medicine, Gifu City, Japan. ${ }^{2}$ Department of Plastic and Reconstructive Surgery, Gifu University Graduate School of Medicine, Gifu City, Japan.

Received: 9 August 2021 Accepted: 2 December 2021

Published online: 14 December 2021

\section{References}

1. Brieley JD, Gospodarowicz MK, Wittekind C. TNM classification of malignant tumours. 8th ed. Hoboken: Wiley-Blackwell; 2017.

2. Tanaka Y, Ueno T, Yoshida N, Akutsu Y, Takeuchi H, Baba H, et al. The effect of an elemental diet on oral mucositis of esophageal cancer patients treated with DCF chemotherapy: a multi-center prospective feasibility study (EPOC study). Esophagus. 2018:15:239-48.

3. Tanaka Y, Yoshida K, Yamada A, Tanahashi T, Okumura N, Matsuhashi N, et al. Phase II trial of biweekly docetaxel, cisplatin, and 5-fluorouracil chemotherapy for advanced esophageal squamous cell carcinoma. Cancer Chemother Pharmacol. 2016;77:1143-52.

4. Bartels HE, Stein HJ, Siewert JR. Respiratory management and outcome of non-malignant tracheo-bronchial fistula following esophagectomy. Dis Esophagus. 1998;11(2):125-9.

5. Buskens CJ, Hulscher JB, Fockens P, Obertop H, van Lanschot JJ. Benign tracheo-neo-esophageal fistulas after subtotal esophagectomy. Ann Thorac Surg. 2001;72(1):221-4.

6. Mangi AA, Gaissert HA, Wright CD, Allan JS, Wain JC, Grillo HC, et al. Benign broncho-esophageal fistula in the adult. Ann Thorac Surg. 2002;73(3):911-5.

7. Shen KR, Allen MS, Cassivi SD, Nichols FC 3rd, Wigle DA, Harmsen WS, et al. Surgical management of acquired nonmalignant tracheoesophageal and bronchoesophageal fistulae. Ann Thorac Surg. 2010;90(3):914-8.

8. Yasuda T, Sugimura K, Yamasaki M, Miyata H, Motoori M, Yano M, et al. Ten cases of gastro-tracheobronchial fistula: a serious complication after esophagectomy and reconstruction using posterior mediastinal gastric tube. Dis Esophagus. 2012;25(8):687-93.

9. Schweigert M, Dubecz A, Beron M, Muschweck H, Stein HJ. Management of anastomotic leakage-induced tracheobronchial fistula following oesophagectomy: the role of endoscopic stent insertion. Eur J Cardiothorac Surg. 2012;41(5):e74-80.

10. Kuwabara S, Tonouchi A, Manabe S, Sudo N, Katada T, Ishino S, et al. Treatment strategy for benign gastric tube-tracheobronchial fistula after esophagectomy for esophageal cancer: 9 case reports and review of the literature. Esophagus. 2013;10:135-43.

11. Wang $\mathrm{S}$, Tachimori $\mathrm{Y}, \mathrm{H}$. kamura N, Igaki H, Kishino T, Nakazato H. A retrospective study on nonmalignant airway erosion after right transthoracic subtotal esophagectomy: incidence, diagnosis, therapy, and risk factors. Ann Thorac Surg. 2014;97(2):467-73.

12. Morita M, Saeki H, Okamoto T, Oki E, Yoshida S, Maehara Y. Tracheobronchial fistula during the perioperative period of esophagectomy for esophageal cancer. World J Surg. 2015;39(5):1119-26.

13. Lambertz R, Hölscher AH, Bludau M, Leers JM, Gutschow C, Schröder W. Management of tracheo- or bronchoesophageal fistula after Ivor-Lewis esophagectomy. World J Surg. 2016;40(7):1680-7.

14. Balakrishnan A, Tapias L, Wright CD, Lanuti MX, Gaissert HA, Mathisen DJ, Muniappan A. Surgical management of post-esophagectomy tracheobronchial-esophageal fistula. Ann Thorac Surg. 2018;106(6):1640-6.

15. Wang C, Li C, Yang X, Mao W, Jiang Y, Wu J, et al. The classification and treatment strategies of post-esophagectomy airway-gastric fistula. J Thorac Dis. 2020;12(7):3602-10.

16. Salassa JR, Pearson BW, Payne WS. Gross and microscopical blood supply of the trachea. Ann Thorac Surg. 1977;24(2):100-7.
17. Caronia FP, Fiorelli A, Santini M, Alfano R, Castorina S. A new technique to repair huge tracheo-gastric fistula following esophagectomy. Ann Transl Med. 2016;4(20):403.

18. Bamba T, Kosugi S, Kanda T, Koyama Y, Suzuki T, Hatakeyama K. Successful treatment for a benign esophagorespiratory fistula with perioperative nutritional management and multistep esophageal bypass operation: a case report. Esophagus. 2008;5:93-7.

19. Ibuki Y, Hamai Y, Hihara J, Taomoto J, Kishimoto I, Miyata Y, et al. Emergency escape surgery for a gastro-bronchial fistula with respiratory failure that developed after esophagectomy. Surg Today. 2015;45(3):369-73.

20. Hara K, Matsunaga T, Fukumoto Y, Miyauchi W, Kono Y, Shishido Y, et al. Successful preservation of the proximal stomach tube by evaluating blood flow using indocyanine green for gastric tube cancer: a case report. Surg Case Rep. 2020;6(1):85.

21. Miyauchi W, Shishido Y, Kono Y, Murakami Y, Kuroda H, Fukumoto Y, et al. Less invasive surgery for remnant stomach cancer after esophago-proximal gastrectomy with ICG-guided blood flow evaluation: a case report. Yonago Acta Med. 2018;61(3):187-91.

22. Saito T, Yano M, Motoori M, Kishi K, Fujiwara Y, Shingai T, et al. Subtotal gastrectomy for gastric tube cancer after esophagectomy: a safe procedure preserving the proximal part of gastric tube based on intraoperative ICG blood flow evaluation. J Surg Oncol. 2012;106(1):107-10.

23. Sonomura J, Shimizu T, Taniguchi K, Lee SW, Tanaka R, Imai Y, et al. Esophago-bronchial fistula treated by the Over-The-Scope-Clipping (OTSC) system with argon beam electrocoagulation: a case report. Medicine. 2021;100(4):244-94.

24. Nagami Y, Ominami M, Sakai T, Fukunaga S, Tanaka F, Taira K, et al. Endoscopic closure of refractory esophageal fistula after esophagectomy using polyglycolic acid sheets: a pilot study. Endosc Int Open. 2020;8(5):E591-5

\section{Publisher's Note}

Springer Nature remains neutral with regard to jurisdictional claims in published maps and institutional affiliations.

Ready to submit your research? Choose BMC and benefit from:

- fast, convenient online submission

- thorough peer review by experienced researchers in your field

- rapid publication on acceptance

- support for research data, including large and complex data types

- gold Open Access which fosters wider collaboration and increased citations

- maximum visibility for your research: over 100M website views per year

At BMC, research is always in progress.

Learn more biomedcentral.com/submissions 